\title{
Clinical signs of pneumonia in infants under 2 months
}

\author{
Sunit Singhi, Anil Dhawan, Sudha Kataria, B N S Walia
}

\begin{abstract}
To determine clinical signs that can predict pneumonia (confirmed by radiography) in infants under 2 months of age, 101 infants with pneumonia and 150 with an upper respiratory infection (but not pneumonia) were studied. Ten infants with pneumonia and 15 with an upper respiratory infection did not have the cough and/or difficult (or rapid) breathing that are recommended as 'entry criteria' by the World Health Organisation (WHO). The remaining infants met WHO entry criteria; in them sensitivity and specificity of respiratory rate $\geqslant 60 / \mathrm{min}$ and/or severe chest indrawing to diagnose pneumonia was $85 \%$ and $97 \%$ respectively. Addition of four non-specific signs (stopped feeding well, looked sick, temperature $\geqslant 38^{\circ} \mathrm{C}$, and abdominal distension) to respiratory rate $\geqslant 60 / \mathrm{min}$ and/or chest indrawing for case identification resulted in a $7 \%$ gain in sensitivity but $22 \%$ loss of specificity. Addition of nasal flaring improved the sensitivity by $6 \%$ without loss of specificity. However, the non-specific signs were the only clue to diagnosis in five infants weighing $\leqslant 2500 \mathrm{~g}$. At age $<7$ days, a weight $\leqslant 2500 \mathrm{~g}$ and cyanosis were associated with significantly higher risk of mortality. These findings support the use of a respiratory rate $\geqslant 60 / \mathrm{min}$ and/or chest indrawing for identification of pneumonia, and suggest addition of nasal flaring to the criteria for case identification in infants under 2 months with cough and/or difficult or rapid breathing.

(Arch Dis Child 1994; 70: 413-417)
\end{abstract}

In many developing countries 20 to $30 \%$ of all deaths from acute respiratory infections in children under 5 years occur during the first two months of life, ${ }^{1}$ mostly as a result of bacterial pneumonia. To meet this challenge, the World Health Organisation (WHO) programme to control acute respiratory infections has special guidelines for management of these infections in infants under 2 months of age for use of primary health workers and small hospitals. These guidelines deal with identification of pneumonia, assessment of its severity, the need for hospitalisation, and type of antibiotic treatment. ${ }^{2}$ The guidelines recommend cough and/or difficult breathing for case finding (entry criteria) and rapid indrawing and several non-specific signs for case identification and assessment of severity. ${ }^{2}$ Inclusion of non-specific signs (for example stopped feeding well, temperature $\geqslant 38^{\circ}$ or $<35^{\circ} \mathrm{C}$, convulsions, abnormal sleepiness, and abdominal distension) reflects the thinking that young infants may have a less specific clinical presentation of pneumonia, often resembling sepsis, meningitis, or urinary tract infection. ${ }^{3}$ Reports the usefulness of WHO guidelines relating to infants under 2 months especially from developing countries are few and more data are needed. ${ }^{45}$

We have analysed prospectively collected data on infants under 2 months, who were evaluated for complaints of either cough, or fever with runny nose, or fever without any other symptom to determine which clinical signs predicted pneumonia that was confirmed by radiography.

\section{Patients and methods}

Included in the study were 101 infants with pneumonia confirmed by radiography and 150 infants diagnosed to have upper respiratory infection (but not pneumonia). They were attending the paediatric emergency or outpatient clinics of Nehru Hospital, Chandigarh between September 1987 and March 1990 for complaints (history) of either cough, runny nose with fever, or fever without any other systemic symptom. Most of the infants who attended these services come from urban and periurban area of Chandigarh and use the facilities as their first contact point.

The parents were asked if the babies had cough, fever, rapid or difficult breathing, and if they had been feeding normally. No specific definition was used for any of these symptoms, parental perception/assessment was accepted as such. A resident doctor recorded these details and also the respiratory rate, body weight, axillary temperature, whether the infant looked sick, cyanosis, grunting, abdominal distension, nasal flaring and severe chest indrawing, and findings on auscultation of the chest. Chest radiography was performed. Respiratory rate was counted for one full minute by observation without disturbing the child, using a watch that showed seconds. Chest indrawing was defined as per WHO guidelines, ${ }^{3}$ and nasal flaring as visible movement of nares with each respiratory effort. A sick look was defined as the physician's impression based on observation of the infant's level of activity, eye contact, cry, consolability, and facial expression. Infants in whom the onset of symptoms was within a few hours of birth, who had symptoms for longer than one week, and those with underlying heart disease or associated other illness were excluded. 
Chest radiography was performed on all the study patients. These were reviewed by an experienced radiologist (SK) who was not aware of the clinical details. Pneumonia was diagnosed on the basis of radiograph findings of alveolar infiltrates (in 16 infants) or a diffuse increase in central lung markings, that is, interstitial infiltrates (in 51), and segmental or lobar consolidation with or without air bronchograms (in 34). Two infants also had pleural effusions. Peribronchial thickening was grouped along with diffuse increase in central lung markings. Bronchiolitis with typical bilateral hyperinflation on radiography was not included in the study. Cases who were evaluated during the same period and did not have radiographic evidence of pneumonia were diagnosed as having upper respiratory infection.

Interobserver variability was minimal as all the physical findings were verified by one of the authors (AD or SS). In most cases respiratory rate was counted either by one of the authors (AD) who was a resident at that time or by a research resident. In a small number of cases other resident doctors, who were trained in the method of counting, recorded respiratory rate. On the whole there were four observers besides the first author (SS). These were all medical doctors with at least two years' experience in paediatrics. The reference person for determining interobserver variation was the first author (SS), who had extensive experience in teaching and training health workers to detect the clinical signs of acute respiratory infection and had participated in a WHO/AGFUND supported field based study on acute respiratory infection control. For qualitative clinical signs (looking sick, indrawing, nasal flaring, distended abdomen, cyanosis) there was $95 \%$ agreement between $\mathrm{SS}$ and $\mathrm{AD}$ or the research resident who finally recorded the observations. The technical error or interobserver error for respiratory rate was determined from 10-12 pairs of observations. This was calculated as $S e=\Sigma d^{2} / 2 n$ where $S e$ is the mean error, $\mathrm{d}$ is difference between respiratory rate counted by SS and another observer, and $n$ is number of the paired observations. Standard deviation of the difference was also calculated. The maximum mean (SD) interobserver error was $2.5(1.6)$ which was within acceptable limits. Standard error of the Se was determined by formula $\sqrt{ } \mathrm{SD}^{2} / \mathrm{n}$, where SD was standard deviation of interobserver and $\mathrm{n}$ sample size. Standard error of Se was 0.5 and its $95 \%$ confidence interval (CI) 1.1 to $3 \cdot 3$. Standard error of $\mathrm{Se}(2 \mathrm{SD})$ was determined by $\sqrt{ } 3 S^{2} / n$. The $95 \%$ CI was calculated for each one of them from appropriate point on the $t$ distribution for $n-1$ degrees of freedom for 0.05 . The CI was calculated as observed value $\pm(t \times$ standard error). The $95 \%$ CI for standard error of the mean interobserver error was $0 \cdot 2$ to $2 \cdot 4$. The $95 \% \mathrm{CI}$ for the upper limit of agreement was 2.4 to 4.9 and lower limit of agreement was 0.7 to $2 \cdot 1$. These intervals were within acceptable limits.

\section{DATA ANALYSIS}

The frequency of various clinical findings was compared in infants with pneumonia and those with an upper respiratory infection, and among pneumonia patients categorised by absence or presence of cough and/or difficult breathing, respiratory rate $\geqslant 60 / \mathrm{min}$ and/or severe chest indrawing, respiratory rate $\geqslant 60 / \mathrm{min}$, temperature $\geqslant 38^{\circ} \mathrm{C}$, body weight $\leqslant 2500 \mathrm{~g}$, and death. The $\chi^{2}$ test with Yates's correction was used for frequency distribution. The sensitivity and specificity of various clinical signs and their combinations to diagnose pneumonia were calculated. The receiver operating characteristic (ROC) curve was plotted from the specificity and sensitivity of various respiratory rates to determine the respiratory rate which was the best discriminator of pneumonia. The odds ratio for death associated with individual signs and its $95 \%$ CI was calculated by the method applicable to incidence study. ${ }^{6}$

\section{Results}

The frequency of various clinical findings in infants with pneumonia and an upper respiratory infection is shown in table 1. Cough and/or difficult or rapid breathing were present in 91 $(90 \%)$ infants with pneumonia and $135(90 \%)$ of those with an upper respiratory infection. Thus 10 infants with pneumonia did not meet WHO entry criteria. Among 91 infants with pneumonia who satisfied the entry criteria, respiratory rate $\geqslant 60 / \mathrm{min}$ and/or chest indrawing were present in 77 cases (table 2). An additional seven infants had one or more non-specific signs (stopped feeding well in five, abnormally sleepy in three, looked sick in three, distended tense abdomen in three, and temperature $\geqslant 38^{\circ} \mathrm{C}$ in six). At least one specific clue to acute respiratory illness pneumonia was present in all the seven either in form of nasal flaring (three), auscultatory signs (three), or cyanosis (one). On the whole, the current WHO criteria could identify $83 \%(84 / 101)$ of the cases of pneumonia.

Table 1 Study population and frequency of various clinical symptoms and signs. Figures are number (\%)

\begin{tabular}{lccc}
\hline & \multicolumn{3}{c}{$\begin{array}{l}\text { Upper } \\
\text { respiratory }\end{array}$} \\
& $\begin{array}{c}\text { Pneumonia } \\
\text { infection } \\
(n=101)\end{array}$ & $(n=150)$ & $\chi^{2}$ \\
\hline Boys:girls & $69: 31$ & $67: 33$ & $\mathrm{NS}$ \\
Weight $\leqslant 2500 \mathrm{~g}$ & $17(17)$ & $24(16)$ & $\mathrm{NS}$ \\
Age $<7$ days & $15(15)$ & $28(19)$ & $\mathrm{NS}$ \\
Fever & $82(81)$ & $99(66)$ & $7 \cdot 1$ \\
Cough & $80(79)$ & $116(77)$ & $\mathrm{NS}$ \\
Difficult or rapid breathing & $87(86)$ & $32(21)$ & $99 \cdot 1$ \\
Stopped feeding well & $44(43)$ & $18(12)$ & $129 \cdot 0$ \\
Distended abdomen & $8(8)$ & $1(1)$ & $5 \cdot 2$ \\
Grunting & $15(15)$ & $3(2)$ & $13 \cdot 1$ \\
Looked sick & $34(34)$ & $3(2)$ & $45 \cdot 7$ \\
Temperature $\geqslant 38^{\circ} \mathrm{C}$ & $36(36)$ & $48(32)$ & $\mathrm{NS}$ \\
Respiratory rate/min & & $118(79)$ & \\
$\quad<40$ & 0 & $32(21)$ & $146 \cdot 8$ \\
$\geqslant 40$ & $101(100)$ & $32(15)$ & $135 \cdot 7$ \\
$\geqslant 50$ & $91(90)$ & $23(15)$ \\
$\geqslant 60$ & $76(75)$ & $4(3)$ & $146 \cdot 8$ \\
$\geqslant 70$ & $34(34)$ & 0 & $55 \cdot 6$ \\
$\geqslant 80$ & $16(16)$ & 0 & \\
Nasal flaring & $53(52)$ & $1(1)$ & $89 \cdot 3$ \\
Chest indrawing & $42(42)$ & 0 & $69 \cdot 8$ \\
Cyanosis & $17(17)$ & 0 & $24 \cdot 5$ \\
Crepitations & $43(43)$ & $6(4)$ & $54 \cdot 7$ \\
Rhonchi & $30(30)$ & $10(7)$ & $20 \cdot 5$ \\
& & & \\
\hline
\end{tabular}

Critical $\chi^{2}$ value (for $2 \times 2$ table) for $\mathrm{p}<0.05=3.84$, $\mathrm{p}<0.01=6.64, \mathrm{p}<0.001=10 \cdot 83$. 
Table 2 Distribution of infants with pneumonia and those with upper respiratory infection with respect to WHO criteria for case finding (presence of cough and/or rapid for difficult breathing) and case identification (respiratory rate $(R R)>60 / \mathrm{min}$, severe chest indrawing, and non-specific signs)

\begin{tabular}{|c|c|c|}
\hline WHO criteria & Pneumonia & $\begin{array}{l}\text { Upper } \\
\text { respiratory } \\
\text { infection }\end{array}$ \\
\hline \multirow{5}{*}{$\begin{array}{l}\text { (I) Cough and/or rapid (difficult) } \\
\text { breathing present with: } \\
1 . R R \geqslant 60 / m i n \text { and severe } \\
\text { chest indrawing } \\
2 . R R \geqslant 60 / m i n \text { only } \\
\text { 3. Severe chest indrawing only } \\
\text { 4. } R R<60 / \text { min, no chest } \\
\text { indrawing } \\
\text { (a) With non-specific signs } \\
\text { (b) Without non-specific signs } \\
\text { (II) No cough or rapid (or difficult) } \\
\text { breathing } \\
\text { 1. With } R R \geqslant 60 / \text { min } \\
\text { 2. With severe chest indrawing } \\
\text { 3. } R R<60 / \text { min, no chest } \\
\text { indrawing }\end{array}$} & 91 & 135 \\
\hline & $\begin{array}{r}36 \\
35 \\
6\end{array}$ & $\begin{array}{l}\overline{4} \\
0\end{array}$ \\
\hline & $\begin{array}{c}14^{\star} \\
7 \\
7\end{array}$ & $\begin{array}{r}131 \\
30 \\
101\end{array}$ \\
\hline & $\begin{array}{c}10 \dagger \\
5 \\
0\end{array}$ & $\begin{array}{r}15 \\
0 \\
0\end{array}$ \\
\hline & & 15 \\
\hline
\end{tabular}

*Nasal flaring was present in six infants, three in each subgroup with and without non-specific signs.

+ Seven infants had history of fever, all the five with $R R$ $\geqslant 60 / \mathrm{min}$ and two others.

The sensitivity, specificity, and positive and negative predictive values of various clinical signs to diagnose radiological pneumonia in those 226 infants who met the entry criteria are given in table 3 . It may be seen that the addition of four non-specific signs (stopped feeding well, looked sick, temperature $\geqslant 38^{\circ} \mathrm{C}$, and abdominal distension) to chest indrawing and respiratory rate $\geqslant 60 / \mathrm{min}$ was associated with a $7 \%$ gain in sensitivity but $22 \%$ loss of specificity. Exclusion of temperature $\geqslant 38^{\circ} \mathrm{C}$ from the non-specific signs restored the specificity to $88 \%$ while the gain in sensitivity stayed at $6 \%$. In contrast to this, nasal flaring added $6 \%$ to the sensitivity without any loss of specificity and positive predictive value. The ROC curve suggested a respiratory rate $50 / \mathrm{min}$ or more as the best indicator of pneumonia (figure).

Pneumonia without entry criteria (no history of cough or difficult (or rapid) breathing) was found in 10 infants. Four of these infants were older than 1 month of age and had a history of fever and respiratory rate $\geqslant 60 / \mathrm{min}$ with nasal flaring in two, temperature $\geqslant 38^{\circ} \mathrm{C}$ in one, and crepitations in three. Another six infants were under 4 weeks of age (range 3-27 days). Only one of these six infants had a respiratory rate $\geqslant 60 / \mathrm{min}$. In the other five, all weighing $\leqslant 2500 \mathrm{~g}$, with a history of fever, nonspecific signs of severe disease (namely stopped feeding well in three, looked sick in three,

Table 3 Sensitivity, specificity, and positive and non-predictive value of selected clinical signs in 91 infants with pneumonia and 135 with an upper respiratory infection (URI)

\begin{tabular}{|c|c|c|c|c|}
\hline & \multirow{2}{*}{$\begin{array}{l}\text { No of infants with } \\
\text { pneumonia/No } \\
\text { with a URI with } \\
\text { presence of sign }\end{array}$} & \multirow{2}{*}{$\begin{array}{l}\text { Sensitivity/ } \\
\text { specificity } \\
(\%)\end{array}$} & \multicolumn{2}{|c|}{ Predictive value (\%) } \\
\hline & & & Positive & Negative \\
\hline \multirow{3}{*}{$\begin{array}{l}\text { 1. } R R \geqslant 60 / \mathrm{min} \\
\text { 2. } C h e s t \text { indrawing } \\
\text { 3. } R R \geqslant 60 / \mathrm{min} \text { and/or chest indrawing } \\
\text { 4. } R R \geqslant 60 / \mathrm{min} \text { and/or indrawing and/or } \\
\text { non-specific signs } \\
\text { 5. } R R \geqslant 60 / \mathrm{min} \text { and/or indrawing and/or } \\
\text { nasal flaring }\end{array}$} & $\begin{array}{l}71 / 4 \\
42 / 0 \\
77 / 4\end{array}$ & $\begin{array}{l}78 / 97 \\
46 / 100 \\
85 / 97\end{array}$ & $\begin{array}{r}95 \\
100 \\
95\end{array}$ & $\begin{array}{l}87 \\
73 \\
90\end{array}$ \\
\hline & $84 / 34$ & $92 / 75$ & 71 & 93 \\
\hline & $83 / 5$ & $91 / 96$ & 94 & 94 \\
\hline
\end{tabular}

$\mathbf{R}=$ respiratory rate.

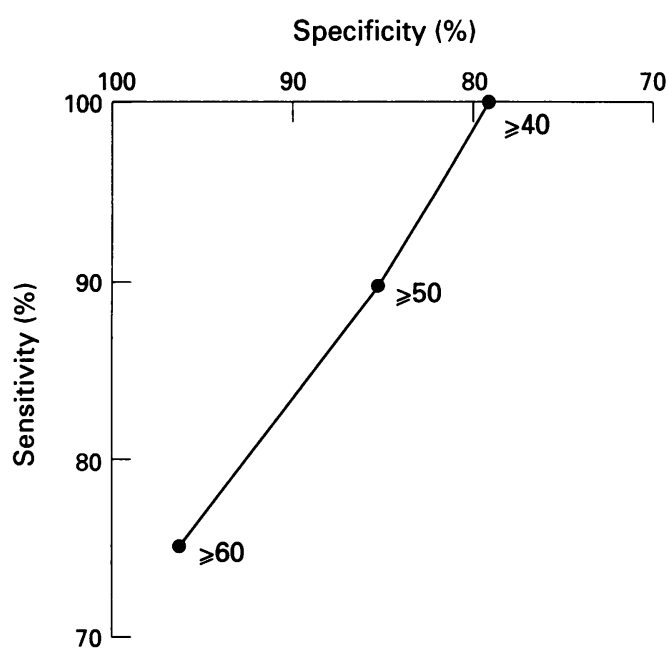

The ROC curve for respiratory rates as indicator of pneumonia in infants under 2 months of age.

temperature $\geqslant 38^{\circ} \mathrm{C}$ in two, and abdominal distension in one) and cyanosis and grunting (one infant) were the only clue to the diagnosis.

Pneumonia without a respiratory rate $\geqslant 60 / \mathrm{min}$ and/or severe indrawing was found in six infants without cough and/or difficult breathing (described above) and in 14 infants with cough and/or difficult breathing. Out of these 14, seven infants had one or more of the non-specific signs (described in first paragraph of results). The other seven infants did not have any of the non-specific signs. Five of them had either nasal flaring (in three) and/or auscultatory signs (decreased air entry on one side and crepitations in three, rhonchi in one). The only signs that the remaining two infants had were a history of fever (but a temperature $<38^{\circ} \mathrm{C}$ on examination) and they looked sick.

Pneumonia with a respiratory rate $<60 /$ min was found in 25 infants. Distribution of these infants with respect to WHO criteria is evident from table 2; six had cough and chest indrawing, seven had cough and/or rapid breathing with non-specific signs, while 13 infants did not fulfil WHO criteria (seven infants met the entry criteria but did not meet any case identification criteria, while six infants did not meet the entry criteria). Infants with a respiratory rate $<60 / \mathrm{min}$ were somewhat younger (mean (SD) age 21 (14) days) compared with those with a respiratory rate $\geqslant 60 / \mathrm{min}$ (27 (17) days) $(\mathrm{p}<0 \cdot 05)$. Nasal flaring and crepitations were less frequent in this group of infants compared with 77 infants with respiratory rate $\geqslant 60 / \mathrm{min}$ (in $60 \%$ and $35 \%$ respectively) $(p<0.05)$. Frequency of the non-specific signs including temperature $\geqslant 38^{\circ} \mathrm{C}$ was similar in the two groups.

Afebrile pneumonia did not differ significantly from febrile pneumonia (temperature $\geqslant 38^{\circ} \mathrm{C}$ ) with regards to the frequency of various clinical findings and the mortality rate. The mean (SD) respiratory rate/min among 36 infants $(65(14) / \mathrm{min})$ who were febrile at the time of presentation was similar to that of 65 afebrile infants $(67(15) / \mathrm{min})$. Also, the respiratory rate did not show any significant correlation with simultaneously recorded axillary temperature $(r=0 \cdot 19)$. 
Table 4 Comparison of frequency of various clinical findings in infants under 2 months with pneumonia with respect to body weight. Figures are number (\%)

\begin{tabular}{|c|c|c|c|}
\hline & $\begin{array}{l}\leqslant 2500 \mathrm{~g} \\
(n=17)\end{array}$ & $\begin{array}{l}>2500 \mathrm{~g} \\
(n=84)\end{array}$ & $\begin{array}{l}p \text { Value } \\
\text { (by } \chi^{2} \\
\text { test) }\end{array}$ \\
\hline Age $<7$ days & $9(53)$ & $6(7)$ & $<0.001$ \\
\hline History of fever & $6(35)$ & $76(90)$ & $<0.005$ \\
\hline Cough & $8(47)$ & $72(86)$ & $<0.005$ \\
\hline Rapid or difficult breathing & $12(71)$ & $75(89)$ & NS \\
\hline Stopped feeding well & $11(65)$ & $33(39)$ & $<0.05$ \\
\hline Distended abdomen & $4(24)$ & $4(5)$ & NS \\
\hline Looked sick & $9(53)$ & $25(30)$ & NS \\
\hline Temperature $\geqslant 38^{\circ} \mathrm{C}$ & $6(35)$ & $30(36)$ & NS \\
\hline \multicolumn{4}{|l|}{ Respiratory rate/min } \\
\hline $\begin{array}{l}\geqslant 50 \\
\geqslant 60\end{array}$ & $\begin{array}{r}15(88) \\
6(35)\end{array}$ & $\begin{array}{l}76(90) \\
70(83)\end{array}$ & $\begin{array}{c}\text { NS } \\
<0.01\end{array}$ \\
\hline Nasal flaring & $8(47)$ & $45(54)$ & NS \\
\hline Chest indrawing & $10(59)$ & $31(37)$ & NS \\
\hline \multirow{3}{*}{$\begin{array}{l}\text { Chest indrawing and/or } R R \\
\geqslant 60 / \text { min } \\
\text { Cyanosis }\end{array}$} & & & \\
\hline & $10(59)$ & $72(86)$ & $\begin{array}{l}<0.05 \\
<0.005\end{array}$ \\
\hline & $8(47)$ & $9(11)$ & $<0.005$ \\
\hline
\end{tabular}

$\mathbf{R}=$ respiratory rate.

Table 5 Frequency of various clinical signs among infants with pneumonia who died and who survived and their relative risk of mortality. Figures are number (\%)

\begin{tabular}{|c|c|c|c|}
\hline & $\begin{array}{l}\text { Died } \\
(n=10)\end{array}$ & $\begin{array}{l}\text { Survived } \\
(n=90)\end{array}$ & $\begin{array}{l}\text { Odds ratio } \\
(95 \% \text { CI) }\end{array}$ \\
\hline Weight $\leqslant 2500 \mathrm{~g}$ & $7(70)$ & $10(11)$ & $11.4(3.3$ to $39 \cdot 7)$ \\
\hline Age $<7$ days & $5(50)$ & $10(11)$ & $5.7(1.9$ to 17.3$)$ \\
\hline Temperature $\geqslant 38^{\circ} \mathrm{C}$ & $5(50)$ & $31(34)$ & - \\
\hline Chest indrawing & $6(60)$ & $35(38)$ & $2 \cdot 2(0 \cdot 70$ to $7 \cdot 2)$ \\
\hline \multicolumn{4}{|l|}{ Respiratory rate/min } \\
\hline$\geqslant 60$ & $7(70)$ & $69(76)$ & - \\
\hline$\geqslant 80$ & $3(30)$ & $22(24)$ & - \\
\hline Stopped feeding well & $3(30)$ & $40(44)$ & - \\
\hline Looked sick & $6(60)$ & $28(31)$ & $2.7(0.8$ to 8.8$)$ \\
\hline Nasal flaring & $5(50)$ & $47(52)$ & - \\
\hline Cyanosis & $6(60)$ & $11(12)$ & $5.7(1.8$ to 18.4$)$ \\
\hline Lobar consolidation & $5(50)$ & $28(31)$ & $2.0(0.63$ to 6.5$)$ \\
\hline
\end{tabular}

Information on outcome of one infant was not recorded.

Out of 17 infants with pneumonia weighing $\leqslant 2500 \mathrm{~g}$ at the time of inclusion in the study, WHO criteria could identify 12 infants. In this group cyanosis and non-specific features such as poor feeding and looking sick were more frequent while a history of fever, cough, and a respiratory rate $\geqslant 60 / \mathrm{min}$ were significantly less frequent (table 4). Five of these infants were identified only on the basis of a history of fever and the presence of non-specific features as discussed above. The risk of mortality was significantly higher in infants $<7$ days of age, and with weight $\leqslant 2500 \mathrm{~g} ; 70 \%$ of all deaths occurred in infants weighing $\leqslant 2500 \mathrm{~g}$ (table 5). The signs included in the WHO guidelines as indicators of very severe disease ${ }^{3}$ were present in eight of the 10 infants who died. However, except for cyanosis none of these signs had a significantly higher risk of mortality.

\section{Discussion}

The clinical diagnosis of pneumonia remains subjective and unreliable for a scientific study. We therefore thought it necessary to use an objective tool such as chest radiography for the diagnosis. The difficulty, inconsistency, and large interobserver difference in eliciting chest findings among physicians ${ }^{78}$ and occurrence of pneumonia in the absence of classic signs such as fever, cough, and rales are well documented. ${ }^{9}$ Moreover, radiological evidence of pneumonia may be absent in many young infants with any combination of pulmonary findings such as tachypnoea, crepitations, or decreased breath sounds. ${ }^{911}$ A chest radiograph taken on the day of death was found to be abnormal in all the 30 newborn infants who had pneumonia on necropsy. ${ }^{12}$ Although not entirely satisfactory in very early pneumonia ${ }^{13}$ and in severely malnourished children, ${ }^{14}$ chest radiography was considered a reliable tool to diagnose pneumonia needing antibiotic treatment ${ }^{13}$ and has been used as the gold standard in two recent studies in older children. ${ }^{13} 15$

Our data have shown that application of cough and/or rapid (or difficult) breathing for case finding and a respiratory rate $\geqslant 60 / \mathrm{min}$, severe chest indrawing, and non-specific signs for case identification could effectively identify $83 \%$ of all pneumonia cases in infants under 2 months. The WHO guidelines thus appear quite satisfactory. Cyanosis and non-specific signs, poor feeding and looking sick, were apparently useful for case identification in infants weighing $\leqslant 2500 \mathrm{~g}$, who were less likely to have a respiratory rate $\geqslant 60 / \mathrm{min}$.

Nasal flaring on its own could have picked up six out of 14 infants with pneumonia who had cough and/or difficult breathing but did not have a respiratory rate $\geqslant 60 / \mathrm{min}$ or severe chest indrawing; three of them did not have even the non-specific signs. The number of pneumonia cases that could have been identified by nasal flaring was similar to the number of cases that were picked up by all the nonspecific signs together. Indeed $88 \%$ of pneumonia cases had either a respiratory rate $\geqslant 60 / \mathrm{min}$, severe chest indrawing, nasal flaring, or cyanosis.

Although the ROC curve showed that the respiratory rate that was the best discriminator of pneumonia was $50 / \mathrm{min}$ and more, we found a respiratory rate $\geqslant 60 / \mathrm{min}$ sensitive enough when used together with severe chest indrawing. Data from some previous studies suggest that tachypnoea on its own may not be a very satisfactory indicator of pneumonia

Table 6 Value of respiratory rate $>60 / \mathrm{min}$ on its own in diagnosis of pneumonia in infants under 2 months of age

\begin{tabular}{|c|c|c|c|c|c|}
\hline \multirow{2}{*}{$\begin{array}{l}\text { Authors } \\
\text { (sample size) }\end{array}$} & \multirow{2}{*}{$\begin{array}{l}\text { Entry } \\
\text { criteria }\end{array}$} & \multirow{2}{*}{$\begin{array}{l}\text { Diagnostic } \\
\text { criteria }\end{array}$} & \multirow{2}{*}{$\begin{array}{l}\text { Sensitivity/ } \\
\text { specificity } \\
(\%)\end{array}$} & \multicolumn{2}{|c|}{ Predictive value (\%) } \\
\hline & & & & Positive & Negative \\
\hline $\begin{array}{l}\text { Berman and Simoes }{ }^{4} \text { (70 infants/49 with } \\
\text { pneumonia) }\end{array}$ & Cough, congestion & $\begin{array}{l}\text { Radiography and/or } \\
\text { clinical signs }\end{array}$ & $63 / 57$ & $77 \cdot 5$ & 40 \\
\hline $\begin{array}{l}\text { Simoes (unpublished) ( } 76 \text { infants } / 59 \text { with } \\
\text { pneumonia) }\end{array}$ & Cough, runny nose & $\begin{array}{l}\text { Clinical signs or } \\
\text { radiography }\end{array}$ & $58 / 88$ & 94 & 38 \\
\hline $\begin{array}{l}\text { Crain } \text { et al }{ }^{11}(228 \text { infants } / 27 \text { with } \\
\text { pneumonia) }\end{array}$ & Fever & Radiography of chest & $48 / 93$ & 50 & 93 \\
\hline $\begin{array}{l}\text { Losek et al }{ }^{10} \text { (115 infants/16 with } \\
\text { pneumonia) }\end{array}$ & Fever & Radiography of chest & $43 / 80$ & 12 & 96 \\
\hline $\begin{array}{l}\text { This study ( } 251 \text { infants/101 with } \\
\text { pneumonia) }\end{array}$ & $\begin{array}{l}\text { Cough or runny nose, } \\
\text { fever }\end{array}$ & Radiography of chest & $75 / 98$ & 96 & 85 \\
\hline
\end{tabular}


(table 6). ${ }^{41011}$ In a recent study, isolated tachypnoea (without other respiratory signs) did not show significant association with pneumonia in febrile infants under 8 weeks of age. ${ }^{11}$ Further, the variation in the respiratory rate caused by the method and duration of counting, state of infant, fever, and several other factors may also influence its usefulness to predict pneumonia. ${ }^{4}$ Our findings, however, support the usefulness of counting the respiratory rate for one full minute by simple observation in an undisturbed infant. Moreover, respiratory rate was useful irrespective of the presence or absence of fever; the frequency of tachypnoea (defined either as a respiratory rate $\geqslant 50 / \mathrm{min}$ or $\geqslant 60 / \mathrm{min}$ ) being similar in the febrile and afebrile infants with pneumonia and coefficient of correlation between respiratory rate and axillary temperature being insignificant. An important issue that needs attention in future is pneumonia without cough and/or difficult breathing. Pneumonia may occur without cough in a substantial proportion of infants. Cough was absent in $21 \%$ of our cases, and in $52 \%$ and $56 \%$ of febrile infants with radiographic pneumonia studied by Crain et al ${ }^{11}$ and Losek et $a l .{ }^{10}$ On the other hand, radiographic pneumonia was found in $12 \%$ of febrile infants under 8 weeks who had a runny nose. ${ }^{11}$ These febrile infants had one or other respiratory sign namely rales and ronchi, which had high positive predictive values but a very low sensitivity. ${ }^{1011} \mathrm{We}$ also picked up all the pneumonia cases without cough on the basis of history of fever. Fever may therefore be included as one of the entry criteria for infants under 2 months.

We are aware of the limitations of a hospital based study and application of this to the general population in the community where disease is likely to be less severe and the proportion of pneumonia cases to those with upper respiratory infection much lower. ${ }^{16}$ For this reason sensitivity and specificity of the clinical signs is likely to be somewhat lower in a community population. None the less, selection of a clinic based sample of infants who had pneumonia confirmed by radiography has helped us in defining the clinical signs that can identify the infants who need antibiotics and where the risk of mortality is at its greatest. ${ }^{5}$
In conclusion, our data support the use of a respiratory rate $\geqslant 60 / \mathrm{min}$ and/or chest indrawing, and suggest the addition of nasal flaring to these, for the identification of pneumonia in infants under 2 months with history of cough and/or difficult or rapid breathing. However, current criteria may miss pneumonia in infants weighing $\leqslant 2500$ g. Pneumonia can occur in such infants without cough, rapid (or difficult) breathing, respiratory rate $\geqslant 60 / \mathrm{min}$, and chest indrawing. Fever, age $<7$ days, and weight $\leqslant 2500 \mathrm{~g}$ were associated with significantly increased risk of death. A more aggressive management strategy may be needed for such infants with pneumonia.

1 Spika JS, Munshi MH, Wojtyniak B, et al. Acute lower respiratory infections a major cause of death in respiratory infections a major cause of
Bangladesh. Ann Trop Paediatr 1989; 9: 33-9.

2 World Health Organisation Programme for the control of acute respiratory infections. Technical bases for the WHO recommendations on management of pneumonia in children at first level health facilities. Geneva: WHO, 1991: 12-6. (WHO/ARI 91/20.)

3 World Health Organisation Programme for the control of acute respiratory infections. Acute respiratory infections in children: case management in small hospitals in developing children: case management in small hospitals in developing countries. A manual for doctors and other senior health

4 Berman S, Simoes EAF. Respiratory rate and pneumonia in infancy. Arch Dis Child 1991; 66: 81-4.

5 Singhi S, Singhi PD. Clinical signs in neonatal pneumonia. Lancet 1990; ii: 1072-3.

6 Morris JA, Gardner MJ. Calculating confidence intervals for relative risks (odds ratios) and standardised ratios and rates. $B M F$ 1988; 296: 1313-6.

7 Smyllie HC, Blendis LM, Armitage P. Observer disagreement in physical signs of the respiratory system. Lancet 1965; ii: 412-3.

8 Spiteri MA, Cook DG, Clarke SW. Reliability of eliciting physical signs in examination of the chest. Lancet 1988; i: 873-5.

9 Leventhal JM. Clinical predictors of pneumonia as a guide to ordering chest roentgenograms. Clin Pediatr (Phila) 1982; 21: 730-4

10 Losek JD, Kishaba RG, Berens RJ, Bonadio WA, Wells RG. Indication for chest roentgenogram in febrile young infants. Pediatr Emerg Care 1989; 5: 149-52.

11 Crain EF, Bulas D, Bijur PE, Goldman HS. Is a chest radiograph necessary in the evaluation of every febrile infant less than 8 weeks of age. Pediatrics 1991; 88: 821-4.

12 Haney PJ, Bohlman M, Sun CCJ. Radiographic findings in neonatal pneumonia. American fournal of Radiology 1984; 143: 23-6.

13 Harari M, Shann F, Spooner V, Meisner S, Carney M, Compo JD. Clinical signs of pneumonia in children. Lancet 1991 ; ii: $928-30$.

14 Doherty JF, Dikhuizen FT, Moule N, Golden MHN. WHO guidelines on detecting pneumonia in children [letter]. Lancet 1991; ii: 1454 .

15 Usha N, Katariya S, Walia BNS. Simple clinical signs of lower respiratory infection. Trop Doct 1990; 20: $158-60$

16 World Health Organisation. Guidelines for research on acute respiratory infections: memorandum from a WHO meeting. Bull World Health Organ 1982; 60: 521-33. 